\title{
Pembuatan Sistem Informasi Retribusi Pelayanan Kesehatan Hewan Kota Pangkalpinang
}

\author{
Riki Afriansyah*1, Linda Fujiyanti ${ }^{2}$ \\ 1,2Program Studi Teknologi Rekayasa Perangkat Lunak, Jurusan Teknik Elektro dan Informatika, \\ Politeknik Manufaktur Negeri Bangka Belitung \\ *e-mail: riki.afrian@gmail.com ${ }^{1}$
}

\begin{abstract}
In the management of animal health service fees, Pangkalpinang City still has various obstacles, especially in managing the recapitulation of revenue reports, deposit reports and tickets that still use manual methods. By using an information system, the management and control of animal health service fees will be easier so as to minimize the occurrence of errors in data processing. To build an information system on animal health service charges using the waterfall model method. This animal health service levy information system integrates software with hardware and computer networks. To test the information system of pangkalpinang animal health service levies using the black box testing method.
\end{abstract}

Keywords: retribution, information systems, device integration, waterfall model, black box testing

\begin{abstract}
Abstrak
Dalam pengelolaan retribusi pelayanan kesehatan hewan kota pangkalpinang masih memiliki berbagai kendala terutama dalam pengelolaan rekapan laporan penerimaan, laporan setoran dan karcis yang masih menggunakan cara manual. Dengan menggunakan sistem informasi maka pengelolaan dan pengontrolan retribusi pelayanan kesehatan hewan akan lebih mudah sehingga meminimalkan terjadinya kesalahan dalam pengolahan data. Untuk membangun sistem informasi retribusi pelayanan kesehatan hewan menggunakan metode waterfall model. Sistem informasi retribusi pelayanan kesehatan hewan ini mengintegrasikan perangkat lunak dengan perangkat keras serta jaringan komputer. Untuk melakukan pengujian sistem informasi retribusi pelayanan kesehatan hewan kota pangkalpinang menggunakan metode black box testing.
\end{abstract}

Kata kunci: retribusi, sistem informasi, integrasi perangkat, waterfall model, black box testing

\section{PENDAHULUAN}

UPTD Puskeswan Dinas Pangan dan Pertanian Kota Pangkalpinang adalah sebuah instansi pemerintah daerah yang bergerak di bidang pelayanan kesehatan hewan. Jenis layanan pada UPTD Puskeswan Dinas Pangan dan Pertanian Kota Pangkalpinang terdiri dari: Konsultasi kesehatan hewan, Pemeriksaan kesehatan hewan dan kesehatan masyarakat veteriner, Tindakan medis (operasi kecil dan besar), Pelayanan reproduksi hewan (Inseminasi buatan (IB)/Kawin suntik, pemeriksaan kebuntingan, pertolongan kelahiran), Penerbitan dokumen kesehatan hewan dan kesehatan masyarakat veteriner, Uji laboratorium sederhana (Pemeriksaaan feses, pemeriksaan kerokan kulit), Rawat inap dan penitipan hewan kesayangan, dan Monitoring dan survey penyakit hewan menular. Retribusi pelayanan kesehatan hewan merupakan pembayaran atas pelayanan kesehatan hewan di Puskeswan sebagai sumber penerimaan pendapatan asli daerah. UPTD Puskeswan kota Pangkalpinang diwajibkan untuk memberikan retribusi pelayanan kesehatan hewan sesuai dengan peraturan daerah kota pangkalpinang nomor 6 tahun 2015.

Pengelolaan retribusi pelayanan kesehatan kota pangkalpinang belum menggunakan sistem informasi sehingga pelaporan rekapan penerimaan dan setoran tidak efisien dari sisi waktu padahal laporan tersebut harus segera dilaporkan ke unit lainnya. Selain itu permasalahan lainya yaitu pasien tidak menerima bukti pembayaran dari hasil pelayanan yang telah dilakukan. Hal ini dapat menyebabkan kecurigaan bagi pasien dalam melakukan pembayaran retribusi 
pengobatan. Pelaporan retribusi belum menggunakan database sehingga untuk melakukan rekapan penerimaan dan setoran dilakukan secara manual sehingga tidak efisien. Oleh karena itu diperlukan sebuah sistem informasi retribusi pelayanan kesehatan hewan agar pengelolaan retribusi dapat dilakukan secara lebih akurat, efektif dan efisen serta kemudahan dalam pengontrolan pelaporan retribusi secara realtime. Pemanfaatan Sistem informasi sangat mempermudah dalam pencatatan dan pelaopran transaksi (Harjoseputro \& Adi, 2021). Sistem dana retribusi yang bersifat realtime maka sistem tersebut akan lebih transparan dalam pengelolaan dana retribusi (Mutriani, Sofia, Subroto \& Kurniadi, 2016).

Dari Berbagai refrensi jurnal dapat disimpulkan bahwa dengan adanya sistem informasi retribusi sangat mempermudah instansi pemerintahan maupun swasta dalam pengelolaan retribusi agar lebih efektif dan efisien. Sistem informasi adminsitrasi penerimaan retribusi sangat membantu bendaharawan dalam pengelolaan data retribusi lebih efektif dari sisi waktu (Guslendra, 2018). Belum adanya penerapan sistem retribusi bagi dinas terkait sangat sulit untuk melakukan kegiatan monitoring dan pengawasan pengelolaan dana retribusi (Christianto \& Pamito Agung, 2017) (Vikasari, 2019). Oleh karena itu Sistem informasi retribusi layanan kesehatan hewan dikembangkan agar dapat dikontrol dan dievaluasi oleh instansi terkait secara realtime dan transparan untuk menghindari terjadinya kecurangan dalam pengelolaan hasil retribusi.

Sistem informsi retribusi pelayanan kesehatan hewan yang akan dibangun mempermudah dalam pengelolaan transaksi, laporan rekapan penerimaan, dan setoran secara akurat dan waktu yang sangat singkat karena database dibuat secara terpusat. Dengan adanya database sistem retribusi akan memudahkan dalam penyajian dan pembuatan laporan secara cepat serta mengurangi kesalahan dalam pengelolaan data retribusi(Setyawan, Didin, Syofiawan, Doni, \& Suraya, 2017). Setelah sistem informasi retribusi pelayanan kesehatan hewan dikembangkan maka sistem tersebut perlu diujikan fungsionalitasnya agar sesuai dengan kebutuhan pengguna. Pengujian menggunakan metode blackbox testing dapat diminimalisir kekurangan pada sistem (Salamah \& Khasanah, 2017).

\section{METODE}

Metode yang digunakan dalam pembangunan sistem informasi ini yaitu metode waterfall merupakan sebuah metode yang memiliki beberapa tahapan yang sekuensial sehingga setiap tahapan harus diselesaikan terlebih dahulu sebelum ke tahapan selanjutnya. Adapun tahapan pada metode waterfall sebagai berikut:

1. Analisa Kebutuhan: tahapan ini merupakan menganalisa kebutuhan sistem yang akan dibangun seperti observasi lapangan untuk pengumpulan data dan informasi dalam membangun sistem agar sesuai dengan kebutuhan.

2. Desain Sistem: membuat rancangan perangkat lunak sebelum dilakukan pengkodingan yaitu membuat UML Diagram. Perancangan perangkat lunak dengan menggunakan UML membuat kebutuhan class dalam perangkat lunak tergambar dengan jelas (Putra \& Andriani, 2019). UML merupakan bahasa pemodelan yang menerapkan konsep pemrograman berorientasi objek yang dapat analisa yang diperlukan oleh sistem(Suendri, 2019).

3. Implementasi: setelah rancangan dibuat tahapan selanjutnya melakukan pengkodingan dengan menggunakan bahasa pemograman website dan database.

4. Pengujian Sistem: Setelah sistem selesai dibuat maka sistem tersebut dilakukan pengujian untuk mengecek kesalahan yang ada pada sistem. Jikw masih ada kesalahan maka akan dilakukan perbaikan sampai sistem dapat berjalan sesuai dengan kebutuhan. Pengujian dilakukan dengan metode blackbox testing. Pengujian black box telah dilakukan terhadap setiap fungsi modul aplikasi, dan hasil pengujian berhasil memenuhi 
5. kebutuhan yang diharapkan pengguna (Ginting, Afrianto, \& Suratun, 2019). metode black box testing diperlukan untuk menguji tingkat kesalahan sistem (Febrian \& Vadlan, 2020).

Pada Tahapan analisa kebutuhan diperoleh dari hasil observasi lapangan dan wawancara. Adapun hasil dari wawancara diperoleh sebagai berikut:

1. Ada empat belas layanan yang dilakukan oleh UPTD Puskeswan Kota Pangkalpinang. Pendataan dan pengolahaan data retribusi menggunakan pencatatan di buku.

2. Kemudian dari hasil catatan retribusi tersebut diolah ke dalam laporan.

3. Pemilik hewan yang melakukan pengobatan hewan tidak menerima bukti pembayaran dari transaksi yang telah dibayar.

4. Bendahara kesulitan dan membutuhkan waktu yang lama dalam melakukan perekapan setoran dan laporan. Sering terjadi kesalahan dalam pengolahan laporan.

5. Kasi Kesmavet kesulitan dalam memonitoring penerimaan retribusi secara realtime.

Dari hasil analisa kebutuhan maka tahapan selanjutnya membuat desain sistem dengan menggunakan metode UML. Adapun lebih detil terkait metode UML sebagai berikut:

1. Use Case Diagram

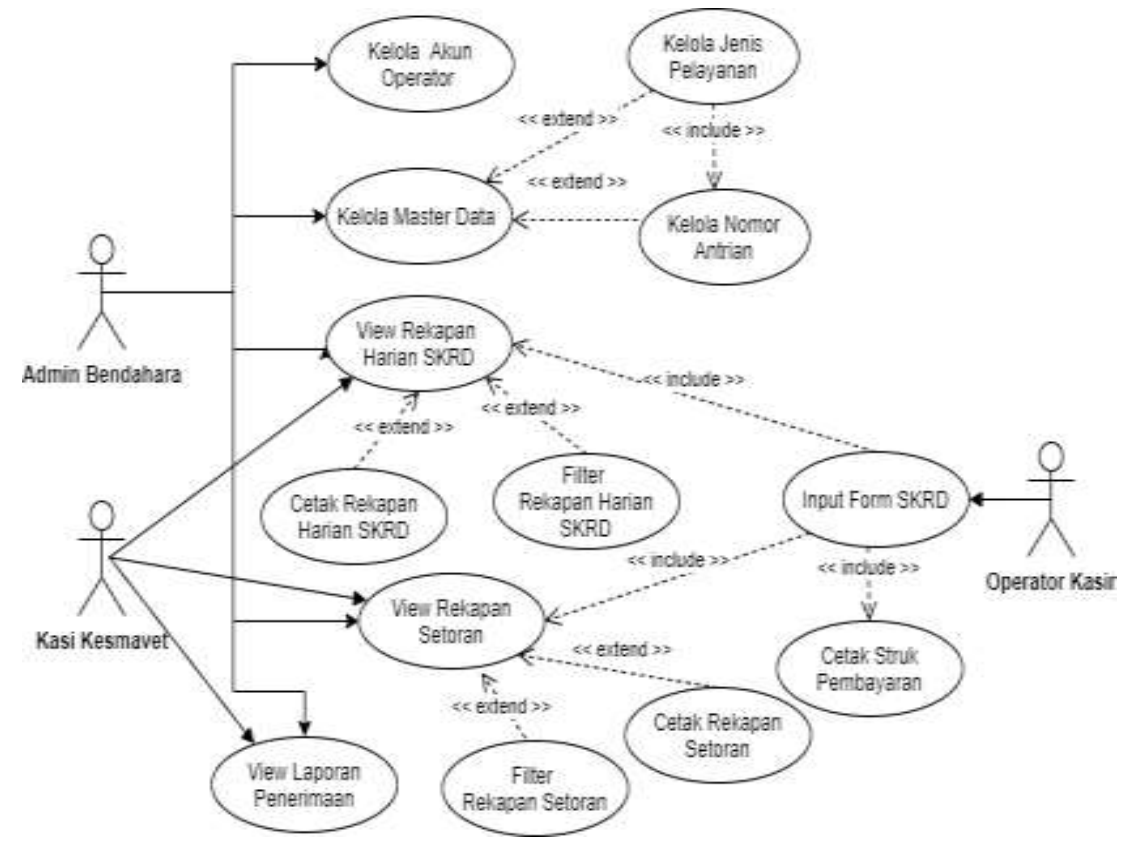

Gambar 1. Use Case Diagram Sistem SKRD

Pada use case diagram terdapat tiga aktor pengguna sistem yang terdiri dari admin bendahara, operator kasir dan kasi kesmavet.

\section{Activity Diagram}

Ada dua activity diagram yang akan dijelaskan yaitu activity diagram dalam proses penginputan transaksi pada sistem skrd dan pencetakan laporan rekapan harian.

a. Activity diagram dalam melakukan penginputan skrd. Operator kasir melakukan login ke dalam sistem skrd. Jika username dan password valid maka menu input form skrd akan tampil setelah itu kasir operator memilih jenis pelayanan maka 
b. no antrian transaksi yang terdiri dari no karcis, sts dan no skrd akan ke generate secara otomatis oleh sistem. Opearator kasir memasukkan jumlah transaksi serta keterangan kemudian data akan tersimpan kedalam database. Setelah data tersimpan maka sistem akan memunculkan informasi transaksi pembayaran dan mencetaknya ke mesin print kasir.

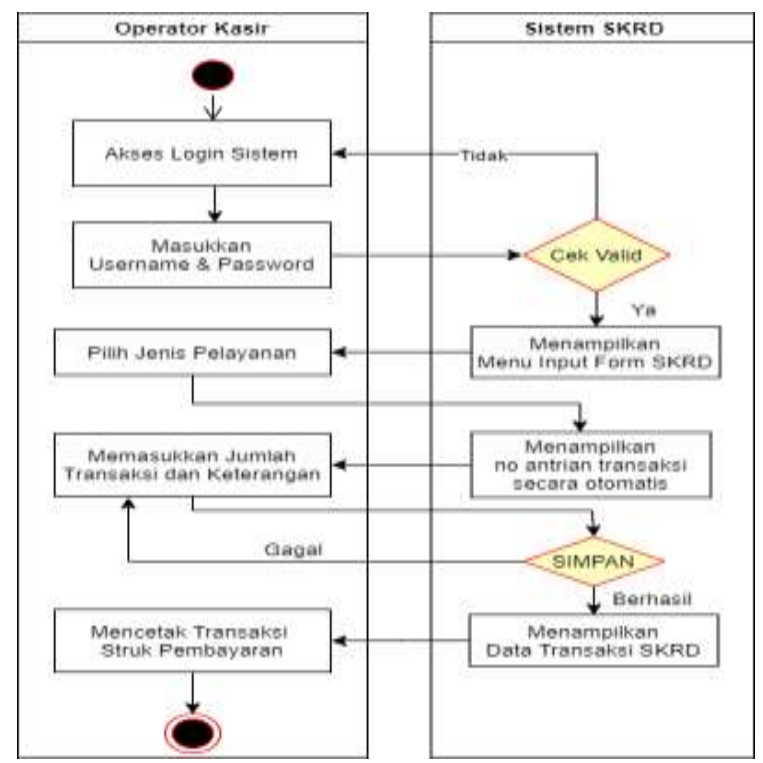

Gambar 2. Activity Diagram Input Transaksi Pada Sistem SKRD

c. Activity diagram proses pencetakan laporan rekapan harian. Pada proses ini yang hanya bisa melakukannya yaitu admin bendahara dan kasi kesmavet dapat melakukan filter data rekapan yang ingin ditampilkan dan dicetak

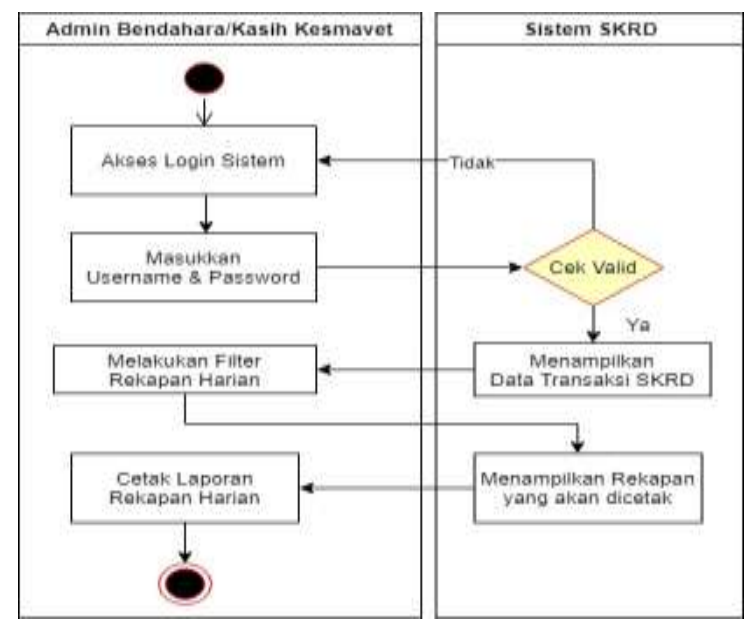

Gambar 3. Activity Diagram Pencetakkan Laporan Rekapan Harian

3. Sequence Diagram

Sequence diagram pada gambar 4 menjelaskan tentang proses operator kasir melakukan pengolahan transkasi ke dalam sistem skrd. 


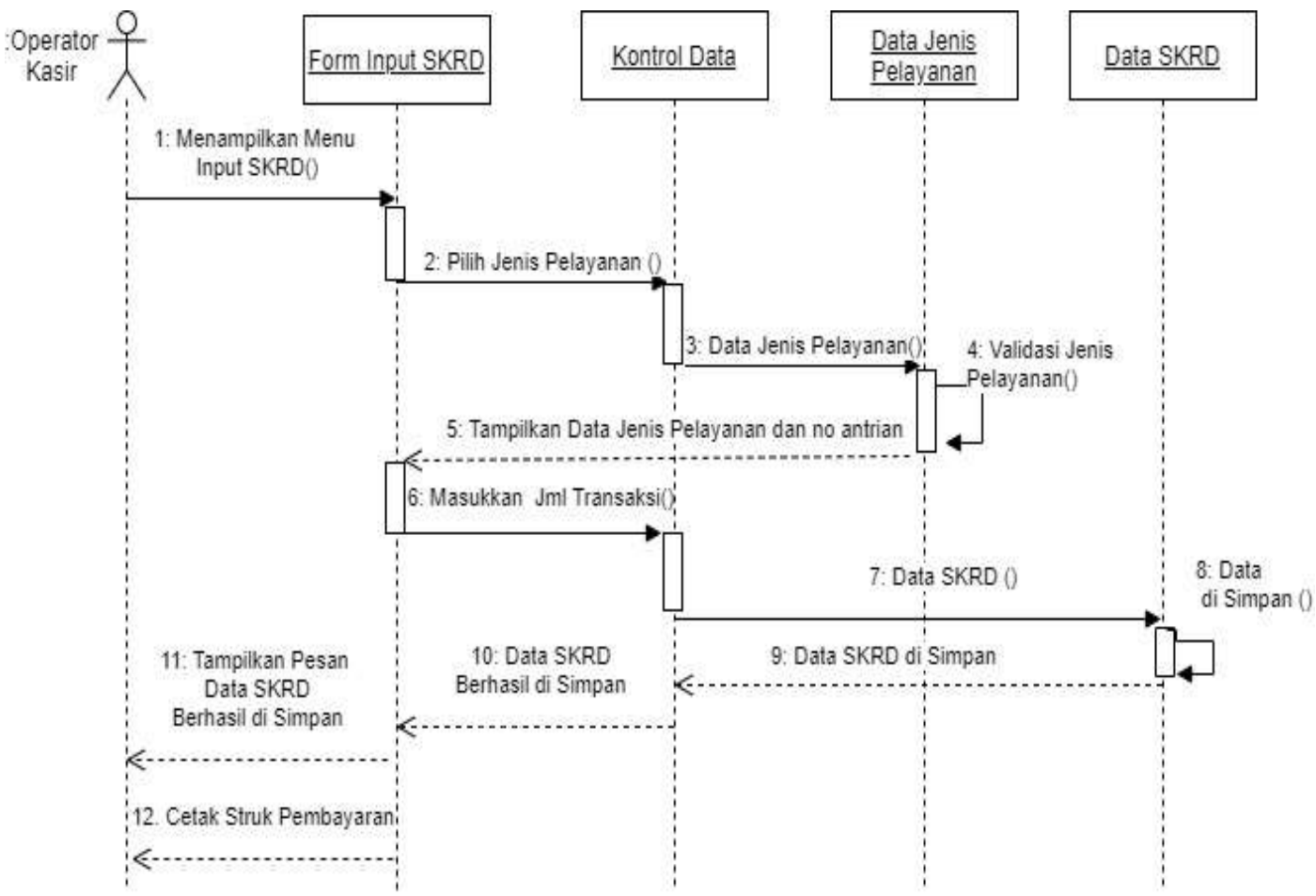

Gambar 4. Sequence Diagram Pengolahan Data Transaksi SKRD

Pada gambar 4 yaitu Operator Kasir memilih menu input SKRD kemudian pada form inputan SKRD akan menampilkan data jenis pelayanan yang ada di data jenis pelayanan pada database dan operator memilih transaksi jenis pelayanan. Ketika operator memilih jenis pelayanan maka no antrian transkasi akan generate secara otomatis oleh sistem. Kemudian operator akan memasukkan jumlah transaksi. Jika data yang dimasukkan valid maka data akan tersimpan pada data skrd pada database serta sistem akan menampilkan notifikasi data berhasil disimpan dan operator data mencetak struk pembayaran.

Gambaran Integrasi Perangkat

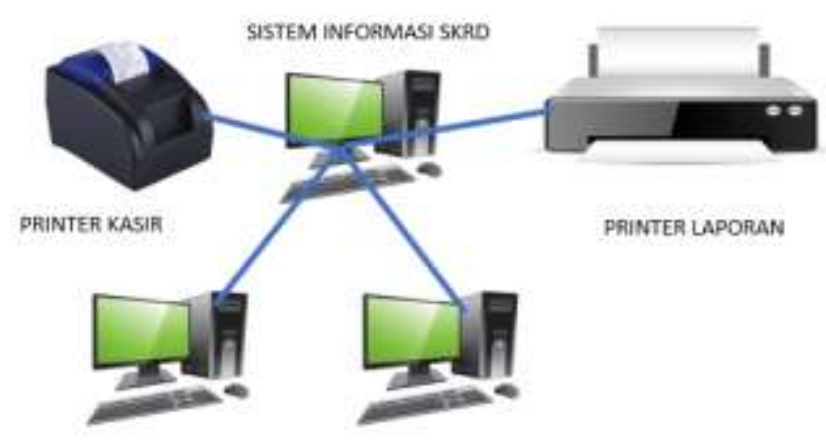

Gambar 5. Gambaran Integrasi Perangkat

Sistem infomasi retribusi pelayanan kesehatan hewan ini mengintegrasikan perangkat lunak dengan perangkat keras serta jaringan komputer. Perangkat keras digunakan untuk melakukan pencetakan struk pembayaran pada printer khusus kasir serta pencetakan laporan rekapan penerimaan dan setoran pada printer lainnya serta jaringan komputer digunakan untuk pengaksesan IP agar bisa diakses di berbagai komputer yang ada pada wilayah cakupan UPTD Puskeswan Kota Pangkalpinang. 


\section{HASIL DAN PEMBAHASAN}

Dalam pembuatan sistem informasi SKRD menggunakan framework codeigniter serta database yang digunakan yaitu MYSQL. adapun tampilan sistem SKRD sebagai berikut:

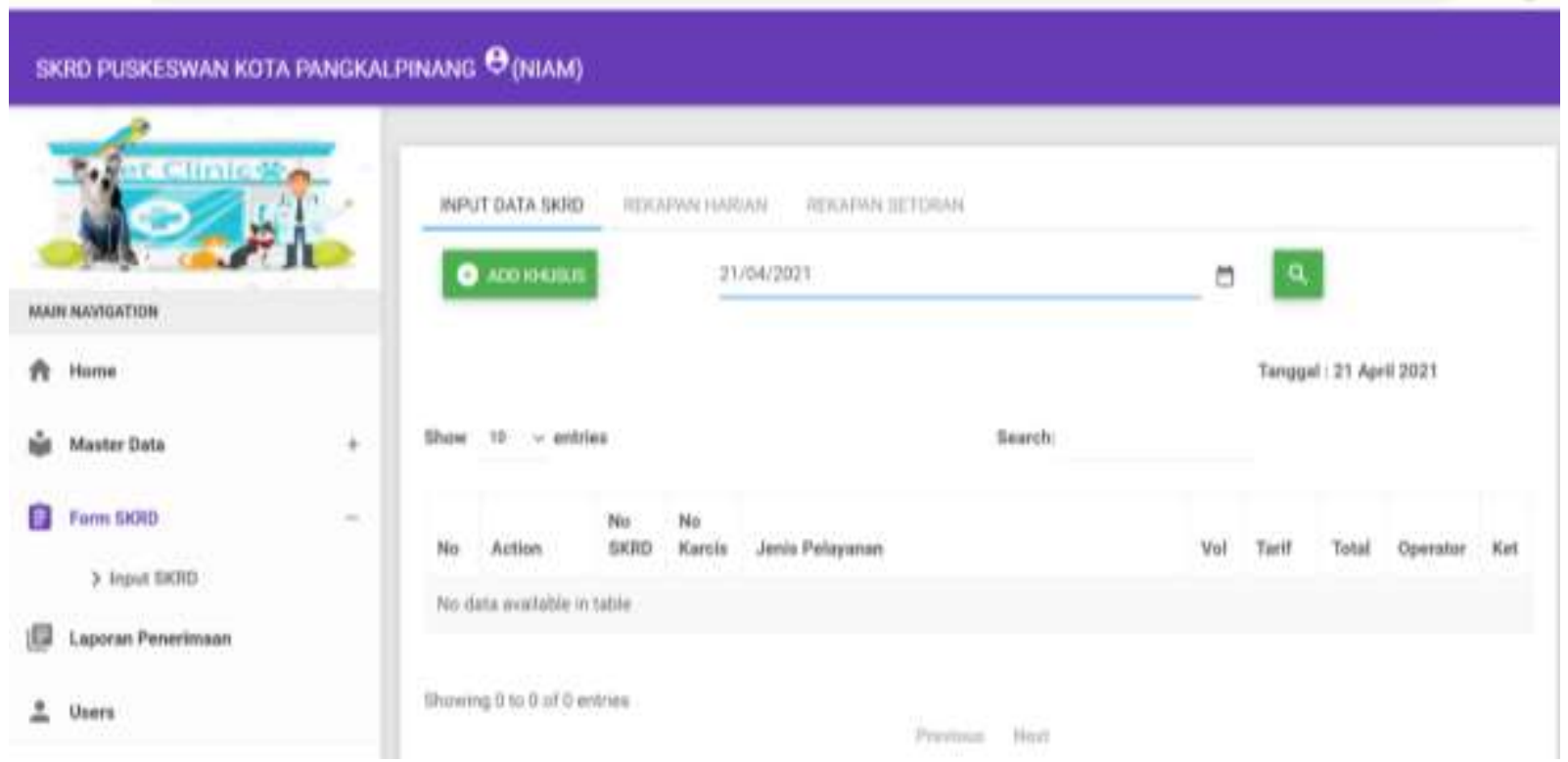

Gambar 6. Tampilan menu pada admin bendahara

1. Menu user

Menu user digunakan untuk mengelola akun operator Kasir. Menu ini hanya digunakan oleh Admin Bendahara.

TAMBAH OPERATOR
NAMA
NO. TELP (Optional)
EMAIL (Optional)
USERNAME

Gambar 7. Menu user

2. Menu Master Data

Menu master data digunakan untuk mengelola data utama dan antrian yang akan digunakan pada pelayanan kasir. Pada menu jenis pelayanan terdapat 3 Tab Menu yaitu jenis pelayanan, sub pelayanan, dan view format pelayanan, 


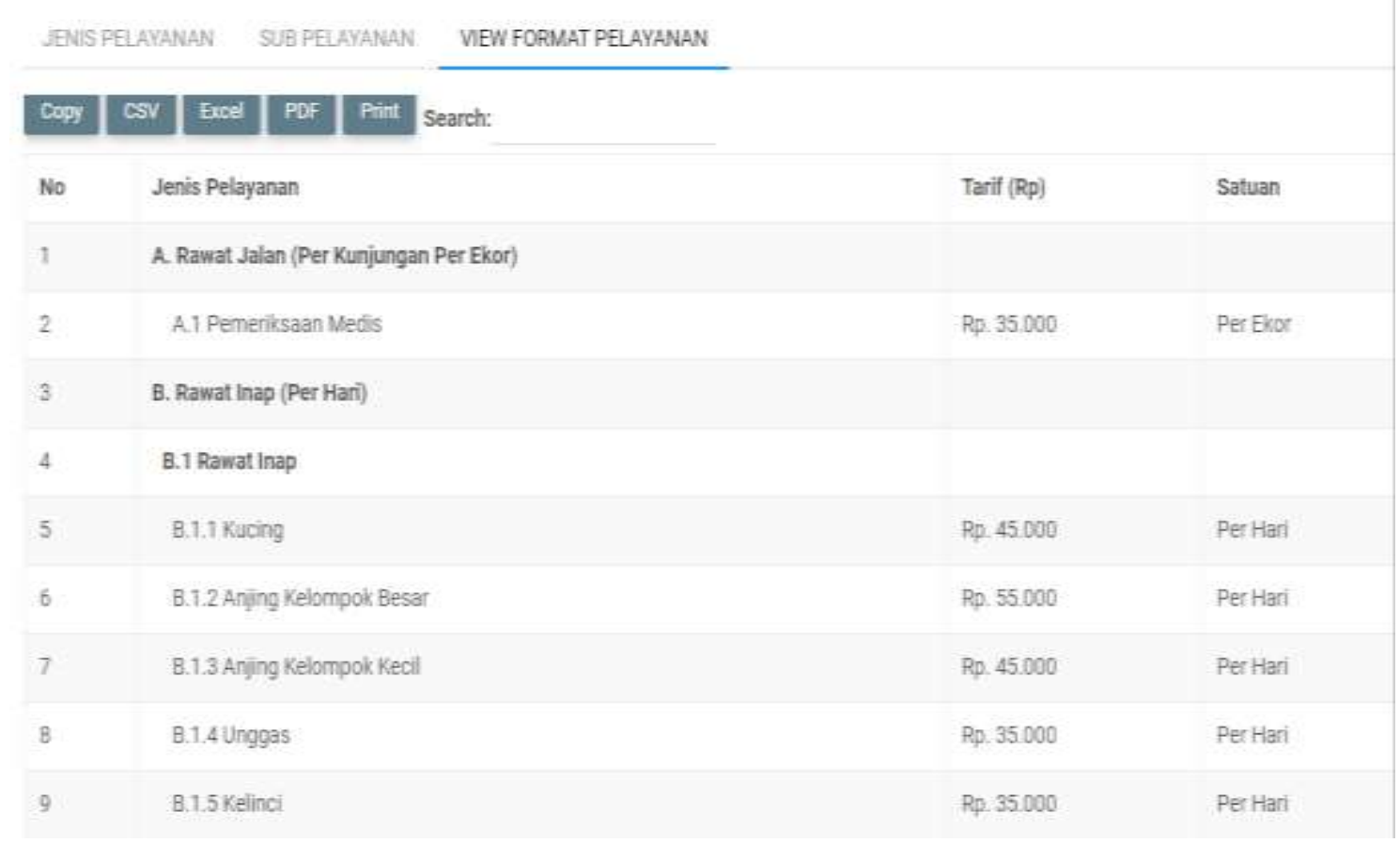

Gambar 7. Menu master data

Menu Nomor Antrian digunakan untuk mengelola No Antrian Karcis, STS, dan SKRD.

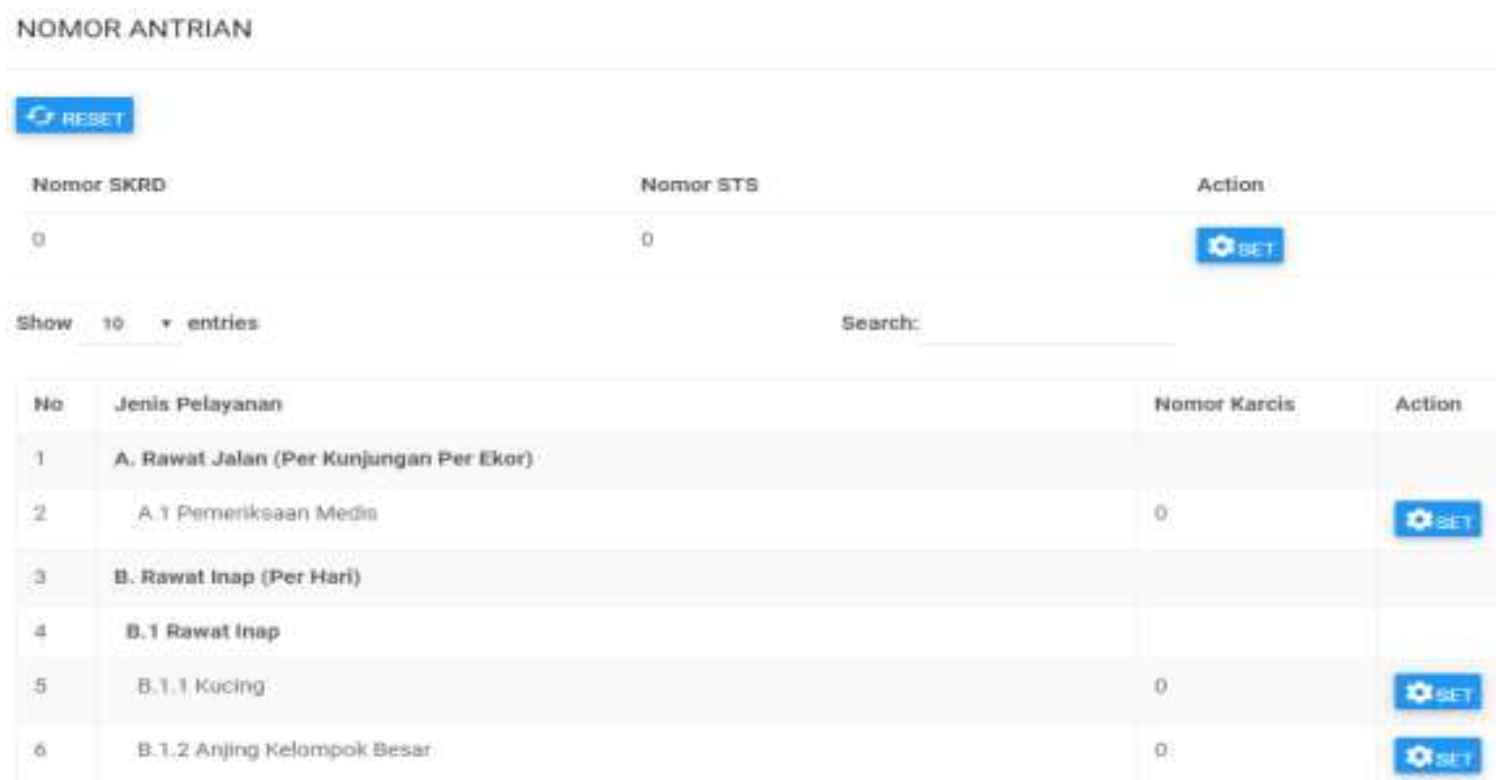

Gambar 8. Menu master data - nomor antrian

3. Menu Form SKRD

Menu input skrd digunakan untuk mengelola transaksi Karcis Pelayanan, Laporan Penerimaan dan Laporan Setoran sesuai dengan transaksi pendataan. 


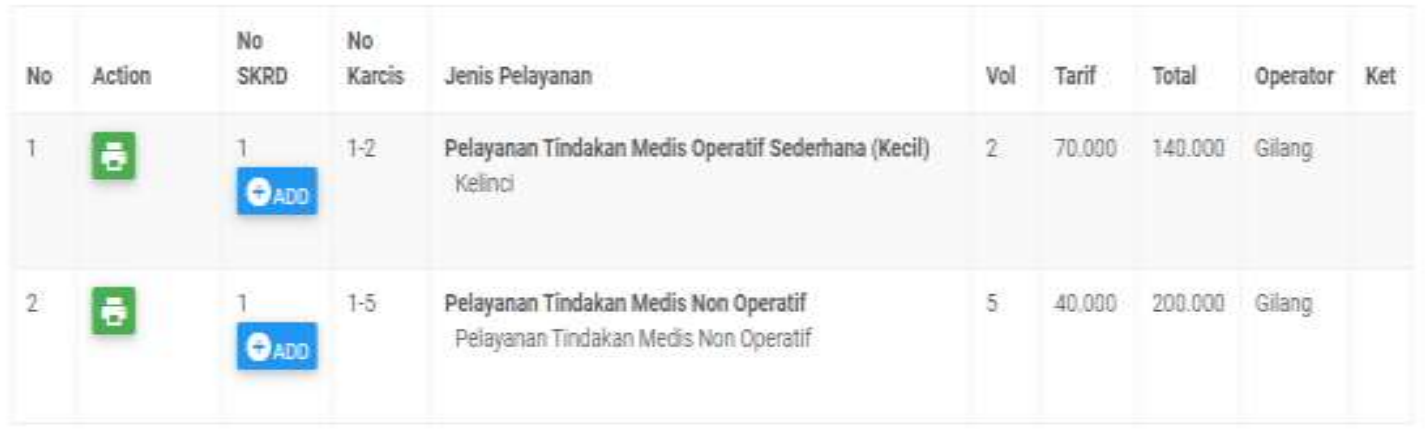

Gambar 9. Menu data transaksi skrd

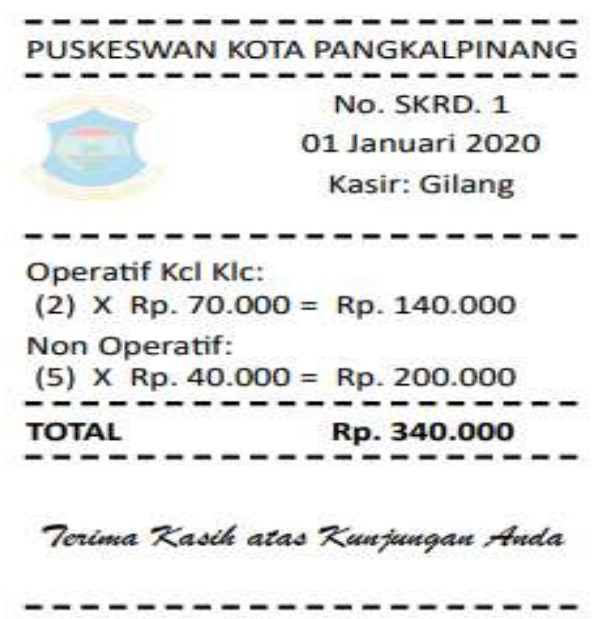

Gambar 10. Format Struk Pembayaran pada sistem

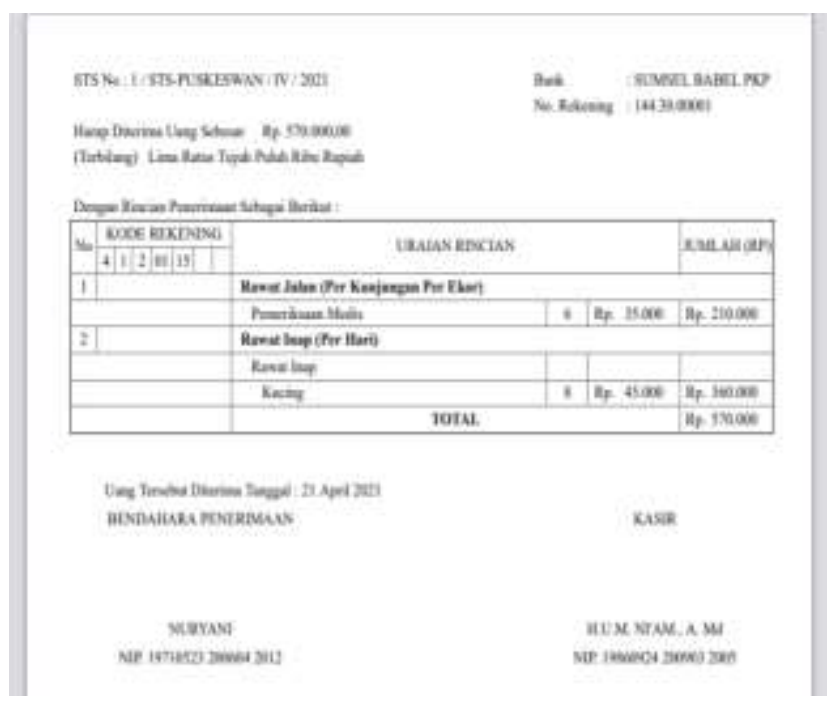

Gambar 11. Laporan Setoran

4. Modul Laporan Penerimaan

Menu ini digunakan untuk melihat dan mencetak laporan setoran, namun untuk tanggal setoran dapat diubah sesuai yang diinginkan. 
REKAPAN PENERIMAAN HARIAN PELAYANAN PUSKESWAN Butan Januari Tahun 2020

\begin{tabular}{|c|c|c|c|c|c|c|}
\hline \multicolumn{6}{|c|}{ URALAN RINCIAN OBUEK } & \multirow{2}{*}{$\begin{array}{l}\text { JUMLAH } \\
\text { [RP] }\end{array}$} \\
\hline $\begin{array}{l}\text { Uralan } \\
\text { A. Rawat Jalan (Per Kunjungan Per Ekor) }\end{array}$ & \multicolumn{3}{|c|}{ Namor Karcis } & Total & Harga & \\
\hline A. 1 Pemeriksaan Medis & 1. & s/d & 2 & 2 & Fip. 35.000 & Rp. 70.000 \\
\hline \multicolumn{7}{|l|}{ 8. Rawat Inop (Per Hari) } \\
\hline \multicolumn{7}{|l|}{ B.I Hawat lnap } \\
\hline \multicolumn{7}{|l|}{ a.1.1 Kucing } \\
\hline \multicolumn{7}{|l|}{ A. 12 Anjing Kelampok Besar } \\
\hline \multicolumn{7}{|l|}{ A.1 3 Anjing Kelampok Kecil } \\
\hline \multicolumn{7}{|l|}{ a.1.4 Ungegas } \\
\hline \multicolumn{7}{|l|}{ A. 15 Kelinci } \\
\hline \multicolumn{7}{|l|}{ B.2. Penittipan } \\
\hline \multicolumn{7}{|l|}{ e. 2.6 Kucing } \\
\hline \multicolumn{7}{|l|}{ A.2.7 Anjing Kelampok Besar } \\
\hline \multicolumn{7}{|l|}{ B. 2 \& Anjing Kelampok Kecil } \\
\hline \multicolumn{7}{|l|}{ A.2. Unggas } \\
\hline \multicolumn{7}{|l|}{ B.2.10 Kelinai } \\
\hline \multicolumn{7}{|l|}{ C. Pelayanan Tindakan Medis Non Operatif } \\
\hline C.1 Pelayanan Tindakan Medis Man Operatif & 1 & $5 / d$ & 5 & 5 & Fip. 40.000 & Ap. 200000 \\
\hline \multicolumn{7}{|c|}{ D. Pelayanan Tindakan Medis Operatif Sederhana (Kecil) } \\
\hline \multicolumn{7}{|c|}{ D.1 Kucing } \\
\hline D2 Anjing Kelompok Besar & & & & & & \\
\hline D 3 Anjing Kelampok Kecil & & & & & & \\
\hline DA Kelinci & 1. & $s / d$ & 2 & 2 & Fp. 70,000 & Rp. 140.000 \\
\hline DS Hewan Eksatik & & & & & & \\
\hline D.6 Ungras & & & & & & \\
\hline D.7 Terrak Kecil & & & & & & \\
\hline D.8 Ternak Besar & & & & & & \\
\hline E. Pelayanan Tindakan Medis Operatif Sedang & & & & & & \\
\hline E1 Kucing & & & & & & \\
\hline E.2 Anjing Kelompol Besar & & & & & & \\
\hline E.3 Anjing Kelarnpok Kecil & & & & & & \\
\hline E.4 Keling & & & & & & \\
\hline E 5 Temak Kedil & & & & & & \\
\hline E.6 Termak Besar & & & & & & \\
\hline E. Pelayanan Tindakan Medis Operatif Besar & & & & & & \\
\hline F,1 Kucing & & & & & & \\
\hline F.2 Anjing Kelarnpok Besar & & & & & & \\
\hline F3 Anjing Kelampoik Kecil & & & & & & \\
\hline F.4 Kelingi & & & & & & \\
\hline F.5 Ternak Kedi & & & & & & \\
\hline F.6 Ternat Besar & & & & & & \\
\hline F.7 Khusus Soctio Caeserea & & & & & & \\
\hline G. Persalinan Normal Dengan Tindakran & & & & & & \\
\hline G.1 Kuacing & & & & & & \\
\hline G.2 Anjing Kelompok Besar & & & & & & \\
\hline G.3 Anjing Keiompoik Kecil & & & & & & \\
\hline
\end{tabular}

Gambar 12. Laporan Penerimaan

Setelah semua menu sistem informasi skrd selesai dikerjakan maka tahapan selanjutnya yaitu melakukan pengujian sistem dengan menggunakan metode blackbox testing. Pengujian dilakukan oleh pegawai UPT Puskeswan Kota Pangkalpinang.

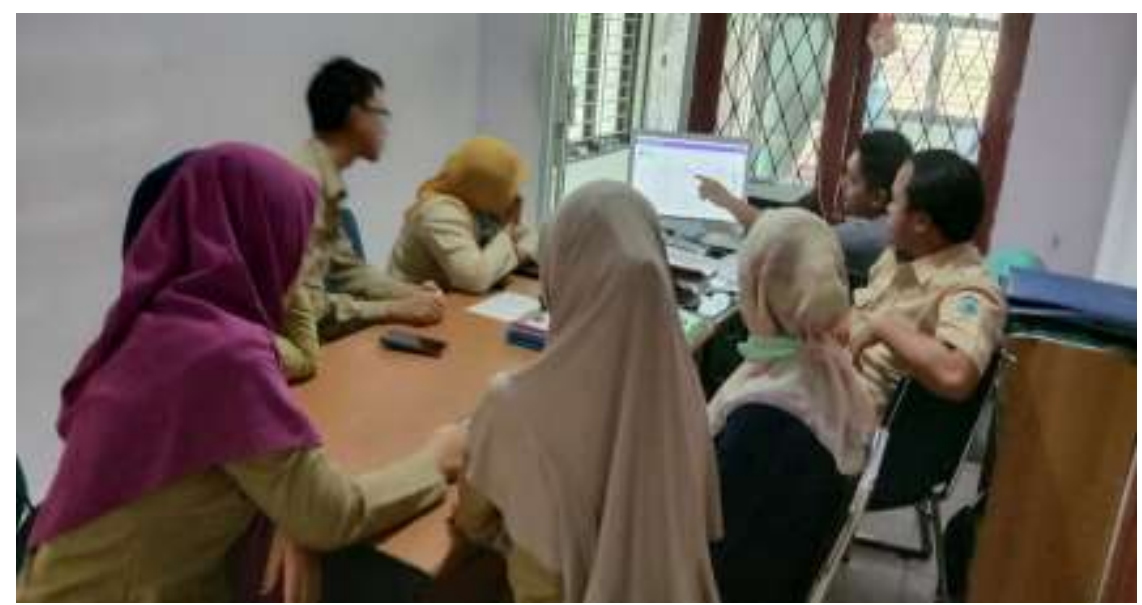

Gambar 13. Pengujian Sistem SKRD 
Adapun hasil pengujian sistem skrd dapat dilihat pada tabel 1 .

Tabel 1. PENGUJIAN SISTEM SKRD DENGAN METODE BLACKBOX TESTING

\begin{tabular}{|c|c|c|c|}
\hline No & Pengujian Fungsi & Aktor & Hasil Pengujian \\
\hline \multirow[t]{2}{*}{1} & Menu Login & & \\
\hline & $\begin{array}{l}\text { Memasukkan } \\
\text { username dan } \\
\text { password. Jika valid } \\
\text { akan menampilkan } \\
\text { menu berdasarkan } \\
\text { hak akses dan jika } \\
\text { tidak valid akan } \\
\text { kembali ke menu } \\
\text { login dan ada } \\
\text { notifikasi kesalahan }\end{array}$ & $\begin{array}{l}\text { Admin Bendahara, } \\
\text { Opeator Kasir dan } \\
\text { Kasi Kesmavet }\end{array}$ & Berhasil \\
\hline \multirow[t]{2}{*}{2} & Menu Master Data & & \\
\hline & $\begin{array}{l}\text { Dapat melakukan } \\
\text { tambah,edit,hapus } \\
\text { dan view data pada } \\
\text { sub menu jenis } \\
\text { pelayanan dan nomor } \\
\text { antrian }\end{array}$ & Admin Bendahara & Berhasil \\
\hline \multirow[t]{4}{*}{3} & Menu Form SKRD & & \\
\hline & $\begin{array}{l}\text { Dapat melakukan } \\
\text { penginputan data } \\
\text { transaksi pelayanan. }\end{array}$ & Operator Kasir & Berhasil \\
\hline & $\begin{array}{l}\text { Dapat mencetak struk } \\
\text { pembayaran, laporan } \\
\text { rekap harian dan } \\
\text { setoran }\end{array}$ & & \\
\hline & $\begin{array}{l}\text { Dapat mencetak } \\
\text { laporan rekap harian } \\
\text { dan setoran SKRD }\end{array}$ & $\begin{array}{l}\text { Admin Bendahara } \\
\text { dan Kasi Kesmavet }\end{array}$ & Berhasil \\
\hline \multirow[t]{2}{*}{4} & Laporan Penerimaan & & \\
\hline & $\begin{array}{l}\text { Dapat mencetak } \\
\text { laporan penerimaan } \\
\text { sesuai filter yang } \\
\text { diingingkan }\end{array}$ & $\begin{array}{l}\text { Admin Bendahara } \\
\text { dan Kasi Kesmavet }\end{array}$ & Berhasil \\
\hline
\end{tabular}

Pengelolaan laporan rekapan skrd bulanan secara manual memerlukan waktu kurang lebih 40 menit sedangkan menggunakan sistem skrd memrlukan waktu kurang dari 1 menit. 
Setelah dilakukan pengujian maka selanjutnya yaitu melakukan pendampingan kepada pengguna sistem yaitu operator, bendahara, dan kasi kesmavet dalam mengelola sistem informasi agar penggunaan sistem informasi dapat berjalan secara efektif. Program pendampingan ini dilakukan selama satu minggu namun untuk memonitoring pengunaan sistem dilakukan per bulan apabila ditemukan masalah pada sistem informasi seperti error dan lainnya.

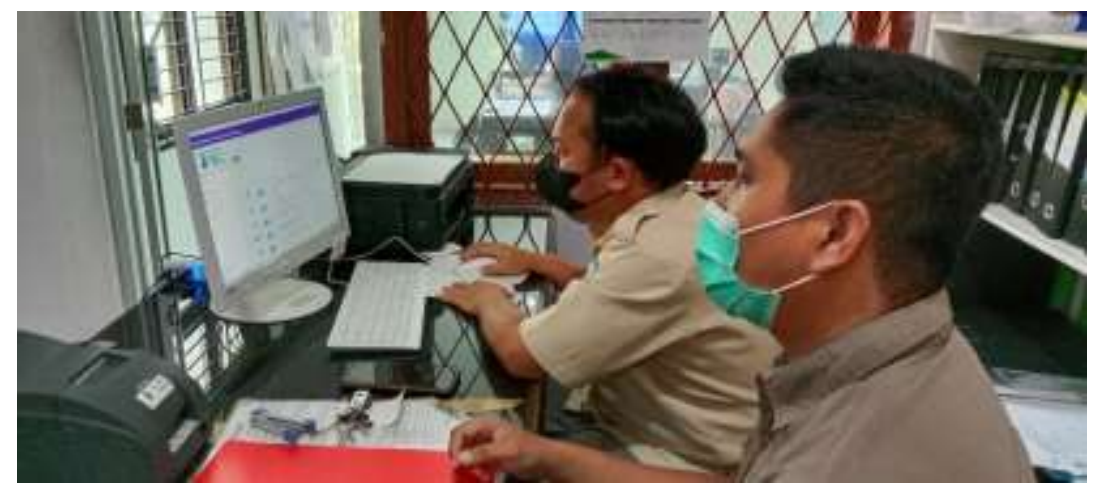

Gambar 14. Pendampingan Pengunaan Sistem Informasi

\section{KESIMPULAN}

Pada proses pengujian dengan metode blackbox testing semua menu sistem skrd dengan tiga aktor yaitu admin bendahara, Operator Kasir dan Kasi Kesmavet dapat berjalan dengan baik. Pengolahan laporan skrd lebih efisien dari sisi waktu dibandingkan dengan cara manual. Adanya integrasi perangkat lunak, jaringan dan perangkat keras dalam hal pencetakan struk pembayaran dan pelaporan. Admin bendahara dan kasi kesmavet dapat memonitoring transaksi skrd scara realtime.

\section{DAFTAR PUSTAKA}

Christianto, P. A., Nurhayati, S., Mujiyono, M., Imtikhanah, S., Angkasa, P., Rismawati, S. D., \& Latief, V. N. (2017). Pengembangan Smart Economy Kota Pekalongan Melalui Penerapan ERetribusi Pelayanan Pasar. Jurnal Pemerintah Kota Pekalongan, 13.

Febrian, V., Ramadhan, M. R., Faisal, M., \& Saifudin, A. (2020). Pengujian pada Aplikasi Penggajian Pegawai dengan menggunakan Metode Blackbox. Jurnal Informatika Universitas Pamulang, 5(1), 61-66.

Ginting, N. B., Afrianto, Y., \& Suratun, S. (2019). Rancang Bangun Aplikasi Sistem Kontrol Perkuliahan Menggunakan Metode Prototype Dan Pengujian Black Box (Studi Kasus: Fakultas Teknik Dan Sains Universitas Ibn Khaldun). Simetris: Jurnal Teknik Mesin, Elektro dan Ilmu Komputer, 10(2), 577-588.

Guslendra, G. (2018). Sistem Informasi Administrasi Penerimaan Retribusi Perusahaan Pada Dinas Pertambangan Dan Energi Kabupaten Solok. Jurnal PTI (Pendidikan Dan Teknologi Informasi) Fakultas Keguruan Ilmu Pendidikan Universita Putra Indonesia" YPTK" Padang, 5(2), 101-113.

Harjoseputro, Yulius., \& Sidhi, Thomas Adi Purnomo. (2021). Pemanfaatan Sistem Informasi Pada Usaha Kecil Menengah Untuk Pencatatan dan PelaporanTransaksi Penjualan. Dinamisia: Jurnal Pengabdian Kepada Masyarakat, 5(5). 
Mutriani, Sofia., Subroto, Imam Much Ibnu., \& Kurniadi, Dedy. (2016). Sistem Informasi Retribusi Pedagang Pasar Kabupaten Semarang. Jurnal Transistor EI,1(1).

Putra, D. W. T., \& Andriani, R. (2019). Unified Modelling Language (UML) dalam Perancangan Sistem Informasi Permohonan Pembayaran Restitusi SPPD. Jurnal Teknoif, 7(1).

Salamah, Umi., \& Khasanah, Fata Nidaul. (2017). Pengujian Sistem Informasi Penjualan Undangan Pernikahan Online Berbasis Web Menggunakan Black Box Testing. Jurnal Information Management For Educators And Professionals, 2(1)

Setyawan, D., \& Syofiawan, D. (2017). Rancang Bangun Sistem Pencatatan Dan Pelaporan Retribusi Puskesmas Sei Panas Kota Batam. Jr: Jurnal Responsive Teknik Informatika, 1(1).

Suendri, S. (2019). Implementasi Diagram UML (Unified Modelling Language) Pada Perancangan Sistem Informasi Remunerasi Dosen Dengan Database Oracle (Studi Kasus: UIN Sumatera Utara Medan). Algoritma: Jurnal Ilmu Komputer Dan Informatika, 2(2), 1.

Vikasari, C. (2019). Sistem Retribusi Parkir Sebagai Pengawasan Pendapatan Asli Daerah Kabupaten Cilacap. Jurnal Nasional Teknologi dan Sistem Informasi, 5(1), 1-8. 